\title{
Financial Counseling Is Associated with Reduced Financial Difficulty Scores in Head and Neck Cancer Patients Treated with Radiation Therapy
}

\author{
Mark Farrugia ${ }^{1,2} \mathbb{D}$, Han Yu ${ }^{3}$, Sung Jun Ma ${ }^{1,2}{ }^{\mathbb{D}}$, Austin J. Iovoli ${ }^{1,2}$, Kayleigh Erickson ${ }^{4}$, Elizabeth Wendel ${ }^{4}$, \\ Kristopher Attwood ${ }^{3}$, Kimberly E. Wooten ${ }^{5}$, Vishal Gupta ${ }^{5}$, Ryan P. McSpadden ${ }^{5}$, Moni A. Kuriakose ${ }^{5}$, \\ Michael R. Markiewicz 5,6,7, Jon M. Chan ${ }^{5}$, Wesley L. Hicks, Jr. ${ }^{5}$, Mary E. Platek 1,4,8, Andrew D. Ray 4 , \\ Elizabeth A. Repasky ${ }^{9}$ and Anurag K. Singh ${ }^{1, *}$
}

Citation: Farrugia, M.; Yu, H.; Ma, S.J.; Iovoli, A.J.; Erickson, K.; Wendel, E.; Attwood, K.; Wooten, K.E.; Gupta, V.; McSpadden, R.P.; et al. Financial Counseling Is Associated with Reduced Financial Difficulty Scores in Head and Neck Cancer Patients Treated with Radiation Therapy. Cancers 2021, 13, 2516. https:// doi.org/10.3390/cancers13112516

Academic Editor: Anne

Déborah Bouhnik

Received: 7 May 2021

Accepted: 19 May 2021

Published: 21 May 2021

Publisher's Note: MDPI stays neutral with regard to jurisdictional claims in published maps and institutional affiliations.

Copyright: (c) 2021 by the authors. Licensee MDPI, Basel, Switzerland. This article is an open access article distributed under the terms and conditions of the Creative Commons Attribution (CC BY) license (https:/ / creativecommons.org/licenses/by/ $4.0 /)$.
1 Department of Radiation Medicine, Roswell Park Comprehensive Cancer Center, 665 Elm Street, Buffalo, NY 14203, USA; Mark.Farrugia@roswellpark.org (M.F.); SungJun.Ma@RoswellPark.org (S.J.M.); Austin.Iovoli@RoswellPark.org (A.J.I.); Mary.Platek@RoswellPark.org (M.E.P.)

2 Jacobs School of Medicine and Biomedical Sciences, University at Buffalo, The State University of New York, 955 Main Street, Buffalo, NY 14203, USA

3 Department of Biostatistics and Bioinformatics, Roswell Park Comprehensive Cancer Center, 665 Elm Street, Buffalo, NY 14203, USA; Han.Yu@RoswellPark.org (H.Y.); Kristopher.Attwood@RoswellPark.org (K.A.)

4 Department of Cancer Prevention and Control, Roswell Park Comprehensive Cancer Center, 665 Elm Street, Buffalo, NY 14203, USA; Kayleigh.Erickson@RoswellPark.org (K.E.); Elizabeth.Wendel@RoswellPark.org (E.W.); Andrew.Ray@RoswellPark.org (A.D.R.)

5 Department of Head and Neck Surgery, Roswell Park Comprehensive Cancer Center, 665 Elm Street, Buffalo, NY 14203, USA; Kimberly.Wooten@RoswellPark.org (K.E.W.); Vishal.Gupta@RoswellPark.org (V.G.); Ryan.McSpadden@RoswellPark.org (R.P.M.); Moni.Kuriakose@RoswellPark.org (M.A.K.); Michael.Markiewicz@RoswellPark.org (M.R.M.); Jon.Chan@RoswellPark.org (J.M.C.); Wesley.Hicks@RoswellPark.org (W.L.H.J.)

6 Department of Oral and Maxillofacial Surgery, School of Dental Medicine, University at Buffalo, The State University of New York, 3435 Main Street, Buffalo, NY 14214, USA

7 Department of Neurosurgery, Jacobs School of Medicine and Biomedical Sciences, University at Buffalo, The State University of New York, 955 Main Street, Buffalo, NY 14203, USA

8 Department of Dietetics, D’Youville College, 270 Porter Avenue, Buffalo, NY 14201, USA

9 Department of Immunology, Roswell Park Comprehensive Cancer Center, 665 Elm Street, Buffalo, NY 14203, USA; Elizabeth.Repasky@roswellpark.org

* Correspondence: Anurag.Singh@RoswellPark.org; Tel.: +1-716-845-5715; Fax: +1-716-845-7616

Simple Summary: Financial toxicity (FT) can be devastating to cancer patients, and solutions are urgently needed. We investigated how providing financial counseling (FC) for head and neck cancer (HNC) patients undergoing radiation therapy impacted patients' financial difficulties at the end of treatment. Beginning in July 2018, a dedicated financial counselor was provided, and all eligible patients received FC. Via a survey, patients who did not have FC reported a significant increase in financial difficulty at the end of treatment however those who had received FC did not report such an increase. Furthermore, in a statistical model FC was associated with significantly lower financial difficulty scores. Based on the findings, the employment of a financial counselor may be a viable, hospital-based approach to begin to address FT in HNC.

Abstract: Background: Financial toxicity (FT) can be devastating to cancer patients, and solutions are urgently needed. We investigated the impact of financial counseling (FC) on FT in head and neck cancer (HNC) patients. Methods: Via a single-institution database, we reviewed the charts of HNC patients who underwent definitive or post-operative radiotherapy, from October 2013 to December 2020. Of these patients, 387 had provided baseline and post-treatment information regarding financial difficulty. In July 2018, a dedicated financial counselor was provided for radiation therapy patients and we subsequently examined the impact of FC on financial difficulty scores. Results: Following the hiring of a dedicated financial counselor, there was a significant increase in the proportion of patients receiving FC ( $5.3 \%$ vs. $62.7 \%, p<0.0001)$. Compared with baseline scores, patients who did not undergo FC had a significant increase in reported financial difficulty at the 
end of treatment $(p=0.002)$. On the other hand, there was no difference in pre- and post-treatment scores in patients who had received FC $(p=0.588)$. After adjusting for gender and nodal status with a multiple linear regression model, FC was significantly associated with change in financial difficulty $(\beta=-0.204 \pm 0.096, p=0.035)$. On average, patients who received FC had a 0.2 units lower change in financial difficulty score as compared with those with the same gender and nodal stage but without FC. Conclusions: Providing a dedicated financial counselor significantly increased the proportion of HNC receiving FC, resulting in the stabilization of financial difficulty scores post-treatment. Based on a multiple linear regression model, FC was independently associated with reduced financial difficulty. The employment of a financial counselor may be a viable, hospital-based approach to begin to address FT in HNC.

Keywords: financial counseling; financial toxicity; head and neck cancer

\section{Introduction}

"Problems a patient has related to the cost of medical care" are defined as financial toxicity (FT) by the National Cancer Institute. Furthermore, FT is also referred to as economic burden, economic hardship, financial burden, financial distress, financial hardship, and financial stress [1]. FT experienced by cancer patients continues to worsen as healthcare costs increase [2-4].

Head and neck cancer (HNC) patients are at particularly high risk for FT as they often require multi-modal therapy, have more out-of-pocket costs, have an increased reliance on cost-coping strategies, and are more likely to suffer production losses as a result of their disease and treatment [5-8]. Consequently, increased financial difficulties in HNC has been linked to impaired quality of life (QOL), increased missed appointments, reduced compliance with medications, and worse medical outcomes including survival [9-11]. Therefore, urgent mitigation strategies for FT among HNC patients are needed.

Reducing treatment costs will require efforts at the national, commercial, institutional, and physician-levels [4] Multiple physician societies have led initiatives to implement cost-effective strategies within clinical guidelines [12-14]. While the appropriate use of cost-effective treatment practices can certainly play a role, this approach alone cannot fully mitigate FT in HNC.

Financial counseling (FC) is a non-treatment-based intervention, which may reduce FT in HNC. In a national survey of cancer centers, $70.2 \%$ of oncologists stated they were reluctant to discuss cost of treatment with patients. Furthermore, while $96.5 \%$ of these centers offered discounts or assistance regarding drug pricing, only $54.4 \%$ offered discussions regarding cost of treatment [15]. Financial counselors can help patients navigate and provide transparency on benefits, expected costs, and cost-mitigating strategies [15]. Despite this, there is a paucity of data examining FC and FT. In this retrospective review, we assessed the impact of standard of care FC on FT in HNC patients undergoing definitive radiation therapy.

\section{Materials and Methods}

\subsection{Patient Population}

With a waiver of consent under approval from the Roswell Park Comprehensive Cancer Center Institutional Review Board for human subject protection (EDR-103707), the charts of HNC patients who underwent definitive or post-operative radiotherapy from October 2013 to December 2020 were reviewed. Of these patients, 408 had provided baseline information regarding financial difficulty. Of these patients, 387 had also completed a survey at the end of treatment. 


\subsection{Patient Data}

Pertinent demographic and clinical data were recorded via chart review. Treatment details have previously been described [16-18]. Unless specifically noted, missing information comprised less than $1 \%$ for each variable. Marital status was documented at the time of treatment. Human papilloma virus (HPV) status was determined by p16 positivity. Staging was performed as per the American Joint Commission on Cancer, 7th edition. Insurance provider information was obtained via the financial counselor. Private insurance included any non-governmental or commercial plans. In instances where a patient had two different insurances, reporting priority was as follows: (1) private, (2) Medicare, and (3) Medicaid. Financial assistance was documented by the financial counselor and defined as institutional assistance with payment for radiation treatment.

\subsection{Financial Counseling}

In July 2018, a dedicated financial counselor was provided for radiation therapy patients. A letter describing benefits, options available to manage expenses, and anticipated expenses by both the patient and their insurance provider was mailed prior to treatment (Supplemental document 1). This letter was not sent in the following circumstances: (i) radiation consult and simulation occurred while patient was hospitalized; (ii) patient had out-of-network plans where we did not have access to fee schedules; and (iii) select patients with dual insurances where coordination of benefits could not be determined. Prior to hiring a dedicated financial counselor, FC was not readily available and only offered at patient request. Notably, cost-estimations were only for radiation therapy and not for other modalities such as chemotherapy or surgery.

\subsection{Financial Difficulty and Quality of Life}

Baseline surveys were completed within 7 days of starting treatment. End of treatment surveys were completed on the last day of radiation therapy. To detail financial difficulty, the European Organisation for Research and Treatment of Cancer (EORTC)-QLQ-C30 survey was used. Question 28 of this questionnaire states "Has your physical condition or medical treatment caused you financial difficulties", with responses recorded on a Likerttype scale, as follows: "1-Not at all, 2-A little, 3-Quite a bit, 4-Very much". To assess change in financial difficulty with treatment, we subtracted the baseline score from the score obtained at the end of treatment. For example, with a post-treatment score of 3 and baseline score of 2, the change of financial difficulty would be reported as 1 . To determine QOL summary scores, baseline responses to the EORTC-QLQ-C30 were used. Scoring was performed as standard [19]. Summary score was calculated as per the EORTC group [20].

\subsection{Statistical Analysis}

Differences between groups were assessed using the Pearson $\chi^{2}$ test for categorical variables and the Wilcoxon test for continuous variables. The Wilcoxon Signed Ranks test was used to compare differences in financial difficulty score, pre- and post-treatment, based on receipt of FC. To examine the change in financial difficulty, the pre-treatment score was subtracted from the post-treatment score. A linear regression model was used to identify variables associated with the change in financial difficulty. The regression coefficients were presented as $\hat{\beta} \pm S E$ (standard error). Those variables with $p$-values $<0.1$ were incorporated into a multiple linear regression model. Variables with $p \leq 0.05$ were considered significant. Statistical analyses were performed using IBM SPSS Version 26 and R 4.0.5.

\section{Results}

Within this cohort of 387 patients, the majority were male $(78.0 \%)$ and married $(60.2 \%)$ (Table 1). Most had private health insurance (49.6\%) followed by Medicare (42.0\%) (Table 1). Nearly half the patients had pharyngeal primaries with $43.9 \%$ of all tumors associated with HPV (Table 1). The most common treatment modality was concurrent chemoradiation 
(62.5\%) and volumetric modulated arc therapy (93.5\%) (Table 1). Over $90 \%$ of the patients were treated in 33-35 fractions (Table 1).

Table 1. Patient demographics.

\begin{tabular}{|c|c|c|c|c|c|c|c|c|c|c|c|}
\hline \multirow{3}{*}{\multicolumn{2}{|c|}{ Patient Demographics }} & \multirow{2}{*}{\multicolumn{3}{|c|}{ All Patients $(n=387)$}} & \multicolumn{6}{|c|}{ Financial Counseling } & \multirow[b]{3}{*}{$p$-Value } \\
\hline & & & & & \multicolumn{3}{|c|}{ No $(n=285)$} & \multicolumn{3}{|c|}{ Yes $(n=102)$} & \\
\hline & & $\begin{array}{c}\text { Median } \\
\text { (IQR) }\end{array}$ & $n$ & $\%$ & $\begin{array}{c}\text { Median } \\
\text { (IQR) }\end{array}$ & $n$ & $\%$ & $\begin{array}{c}\text { Median } \\
\text { (IQR) }\end{array}$ & $n$ & $\%$ & \\
\hline \multicolumn{2}{|c|}{ Age (Years) } & $\begin{array}{c}62 \\
(55.4-68.5)\end{array}$ & & & $\begin{array}{c}62 \\
(55.5-68.5)\end{array}$ & & & $62(55-69)$ & & & 0.717 \\
\hline \multirow{2}{*}{ Gender } & Male & & 302 & $78.0 \%$ & & 225 & $78.9 \%$ & & 77 & $75.5 \%$ & 0.469 \\
\hline & Female & & 85 & $22.0 \%$ & & 60 & $21.1 \%$ & & 25 & $24.5 \%$ & \\
\hline \multirow{7}{*}{ Marital status } & Single & & 73 & $18.9 \%$ & & 67 & $23.5 \%$ & & 6 & $5.9 \%$ & 0.005 \\
\hline & Married & & 233 & $60.2 \%$ & & 163 & $57.2 \%$ & & 70 & $68.6 \%$ & \\
\hline & Divorced & & 48 & $12.4 \%$ & & 30 & $10.5 \%$ & & 18 & $17.6 \%$ & \\
\hline & Widowed & & 23 & $5.9 \%$ & & 16 & $5.6 \%$ & & 7 & $6.9 \%$ & \\
\hline & Unknown & & 8 & $2.1 \%$ & & 7 & $2.5 \%$ & & 1 & $1.0 \%$ & \\
\hline & Separated & & 1 & $0.3 \%$ & & 1 & $0.4 \%$ & & 0 & $0.0 \%$ & \\
\hline & Life partner & & 1 & $0.3 \%$ & & 1 & $0.4 \%$ & & 0 & $0.0 \%$ & \\
\hline \multirow{3}{*}{ Insurance } & Private & & 182 & $49.6 \%$ & & 131 & $48.7 \%$ & & 51 & $52.0 \%$ & 0.545 \\
\hline & Medicare & & 154 & $42.0 \%$ & & 117 & $43.5 \%$ & & 37 & $37.8 \%$ & \\
\hline & Medicaid & & 31 & $8.4 \%$ & & 21 & $7.8 \%$ & & 10 & $10.2 \%$ & \\
\hline \multirow{3}{*}{$\begin{array}{l}\text { Financial } \\
\text { assistance }\end{array}$} & No & & 246 & $63.6 \%$ & & 175 & $61.4 \%$ & & 71 & $69.6 \%$ & 0.321 \\
\hline & Yes & & $\begin{array}{c}29 \\
112\end{array}$ & $\begin{array}{l}7.5 \% \\
28.9 \%\end{array}$ & & 22 & $\begin{array}{l}7.7 \% \\
30.9 \%\end{array}$ & & 7 & $6.9 \%$ & \\
\hline & Missing & & 112 & $28.9 \%$ & & 88 & $30.9 \%$ & & 24 & $23.5 \%$ & \\
\hline \multirow{2}{*}{ Pharynx } & Non-pharynx & & 183 & $47.3 \%$ & & 136 & $47.7 \%$ & & 47 & $46.1 \%$ & 0.776 \\
\hline & Pharynx & & 204 & $52.7 \%$ & & 149 & $52.3 \%$ & & 55 & $53.9 \%$ & \\
\hline \multirow[b]{2}{*}{ HPV status } & Negative & & 217 & $56.1 \%$ & & 156 & $54.7 \%$ & & 61 & $59.8 \%$ & 0.376 \\
\hline & Positive & & 170 & $43.9 \%$ & & 129 & $45.3 \%$ & & 41 & $40.2 \%$ & \\
\hline \multirow{5}{*}{ T stage } & T0 & & 29 & $7.6 \%$ & & 25 & $8.9 \%$ & & 5 & $4.9 \%$ & 0.437 \\
\hline & T1 & & 55 & $14.3 \%$ & & 40 & $14.2 \%$ & & 15 & $14.7 \%$ & \\
\hline & $\mathrm{T} 2$ & & 112 & $29.2 \%$ & & 86 & $30.5 \%$ & & 26 & $25.5 \%$ & \\
\hline & T3 & & 116 & $30.2 \%$ & & 83 & $29.4 \%$ & & 32 & $31.4 \%$ & \\
\hline & $\mathrm{T} 4$ & & 72 & $18.8 \%$ & & 48 & $17.0 \%$ & & 24 & $23.5 \%$ & \\
\hline \multirow{4}{*}{ N stage } & N0 & & 83 & $21.6 \%$ & & 60 & $21.3 \%$ & & 23 & $22.5 \%$ & 0.006 \\
\hline & N1 & & 90 & $23.4 \%$ & & 55 & $19.5 \%$ & & 35 & $34.3 \%$ & \\
\hline & N2 & & 174 & $45.3 \%$ & & 141 & $50.0 \%$ & & 33 & $32.4 \%$ & \\
\hline & N3 & & 37 & $9.6 \%$ & & 26 & $9.2 \%$ & & 11 & $10.8 \%$ & \\
\hline \multirow{4}{*}{ Treatment } & RT & & 28 & $7.2 \%$ & & 18 & $6.3 \%$ & & 10 & $9.8 \%$ & 0.462 \\
\hline & Surgery + RT & & 45 & $11.6 \%$ & & 31 & $10.9 \%$ & & 14 & $13.7 \%$ & \\
\hline & ChemoRT & & 242 & $62.5 \%$ & & 184 & $64.6 \%$ & & 58 & $56.9 \%$ & \\
\hline & $\begin{array}{l}\text { Surgery + } \\
\text { ChemoRT }\end{array}$ & & 72 & $18.6 \%$ & & 52 & $18.2 \%$ & & 20 & $19.6 \%$ & \\
\hline \multirow{2}{*}{ Technique } & VMAT & & 362 & $93.5 \%$ & & 271 & $95.1 \%$ & & 91 & $89.2 \%$ & 0.38 \\
\hline & 3DCRT & & 25 & $6.5 \%$ & & 14 & $4.9 \%$ & & 11 & $10.8 \%$ & \\
\hline \multirow{2}{*}{ Fractions } & $33-35$ & & 355 & $91.7 \%$ & & 269 & $94.4 \%$ & & 86 & $84.3 \%$ & 0.002 \\
\hline & $28-30$ & & 32 & $8.3 \%$ & & 16 & $5.6 \%$ & & 16 & $15.7 \%$ & \\
\hline \multicolumn{2}{|c|}{ QOL summary score } & $\begin{array}{c}81.6 \\
(72.4-87.8)\end{array}$ & & & $\begin{array}{c}82.3 \\
(72.6-88.0)\end{array}$ & & & $\begin{array}{c}79.4 \\
(71.1-86.3)\end{array}$ & & & 0.13 \\
\hline
\end{tabular}

IQR: interquartile range; HPV: human papilloma virus; RT: radiation therapy; ChemoRT: concurrent chemoradiation; VMAT: volumetric modulated arc therapy; 3DCRT: 3-dimensional conformal radiation therapy; QOL: quality of life.

After July 2018, with the hiring of a dedicated financial counselor, the proportion of patients receiving FC increased significantly (5.3\% vs. $62.7 \%, p<0.0001)$. Patients who underwent FC were more likely to be married or formerly married $(p=0.005)$, to have a lower nodal stage $(p=0.006)$, and to undergo fewer radiation fractions $(p=0.002)$ (Table 1$)$.

Compared with baseline scores, patients who did not undergo FC had a significant increase in reported financial difficulty scores at the end of treatment $(p=0.002)$ (Table 2). On the other hand, there was no difference in pre- and post-treatment scores in patients who had received FC $(p=0.588)$ (Table 2$)$. 
Table 2. Financial difficulty scores by receipt of financial counseling.

\begin{tabular}{cccccccccc}
\hline $\begin{array}{c}\text { EORTC QLQ-C30 } \\
\text { Question 28 }\end{array}$ & \multicolumn{7}{c}{ Financial Counseling } \\
\hline & \multicolumn{7}{c}{ No $(\boldsymbol{n}=\mathbf{2 8 5})$} & \multicolumn{3}{c}{ Yes $(\boldsymbol{n}=\mathbf{1 0 2})$} \\
\hline & \multicolumn{2}{c}{ Pre } & \multicolumn{2}{c}{ Post } & \multicolumn{2}{c}{ Pre } & \multicolumn{2}{c}{ Post } \\
\hline Financial Difficulty & $n$ & $\%$ & $n$ & $\%$ & $n$ & $\%$ & $n$ & $\%$ \\
1-Not at all & 172 & $60.4 \%$ & 150 & $52.6 \%$ & 60 & $58.8 \%$ & 59 & $57.8 \%$ \\
2-A little & 69 & $24.2 \%$ & 73 & $25.6 \%$ & 21 & $20.6 \%$ & 25 & $24.5 \%$ \\
3-Quite a bit & 31 & $10.9 \%$ & 45 & $15.8 \%$ & 16 & $15.7 \%$ & 14 & $13.7 \%$ \\
4-Very much & 13 & $4.6 \%$ & 17 & $6.0 \%$ & 5 & $4.9 \%$ & 4 & $3.9 \%$ \\
\hline Pre: pre-treatment: Post: post-treatment.
\end{tabular}

Pre: pre-treatment; Post: post-treatment.

Using a linear regression model, each variable was separately assessed for a potential correlation with change in financial difficulty score following treatment (Table 3$)$. The analysis identified female gender with a lower increase in financial difficulty $(\beta=-0.23 \pm 0.1$, $p=0.02)$. On the other hand, higher nodal positivity $(p<0.05)$ was found to be associated with a larger increase in financial difficulty scores. The univariate analysis also reveals a trend for FC to reduce the increase in financial difficulty, which is marginally significant $(\beta=-0.18 \pm 0.094, p=0.052)$ (Table 3).

Table 3. Correlation with change in financial difficulty by linear regression.

\begin{tabular}{|c|c|c|c|}
\hline Variable & $\beta$ & SE & $p$-Value \\
\hline Female & -0.23 & 0.1 & 0.0242 \\
\hline Married & -0.07 & 0.085 & 0.3971 \\
\hline Financial Counseling & -0.18 & 0.0941 & 0.0515 \\
\hline \multicolumn{4}{|l|}{ Insurance } \\
\hline Private & reference & & \\
\hline Medicare & 0.01 & 0.091 & 0.8694 \\
\hline Medicaid & 0.21 & 0.1616 & 0.199 \\
\hline Financial Assistance & -0.17 & 0.1613 & 0.2913 \\
\hline Age ( $>60$ years) & 0.01 & 0.0846 & 0.9047 \\
\hline Pharynx primary & 0.04 & 0.0834 & 0.6741 \\
\hline \multicolumn{4}{|l|}{ T stage } \\
\hline T0 & reference & & \\
\hline $\mathrm{T} 1$ & -0.1 & 0.189 & 0.605 \\
\hline $\mathrm{T} 2$ & -0.03 & 0.1716 & 0.869 \\
\hline $\mathrm{T} 3$ & -0.14 & 0.171 & 0.4203 \\
\hline $\mathrm{T} 4$ & -0.19 & 0.1811 & 0.2872 \\
\hline \multicolumn{4}{|l|}{$\mathrm{N}$ stage } \\
\hline No & reference & & \\
\hline N1 & 0.25 & 0.1242 & 0.0425 \\
\hline N2 & 0.26 & 0.1089 & 0.016 \\
\hline N3 & 0.38 & 0.1614 & 0.0195 \\
\hline HPV positive & 0.04 & 0.0839 & 0.6183 \\
\hline \multicolumn{4}{|l|}{ Treatment } \\
\hline RT & reference & & \\
\hline Surgery + RT & -0.01 & 0.1969 & 0.9454 \\
\hline ChemoRT & 0.05 & 0.1633 & 0.774 \\
\hline Surgery + ChemoRT & 0.23 & 0.1822 & 0.2112 \\
\hline 3DCRT & 0.02 & 0.1695 & 0.9294 \\
\hline Fractions (28-30) & -0.08 & 0.1512 & 0.5906 \\
\hline QOL summary score & -0.001 & 0.003 & 0.754 \\
\hline
\end{tabular}

SE: standard error; HPV: human papilloma virus; RT: radiation therapy; ChemoRT: concurrent chemoradiation 3DCRT: 3-dimensional conformal radiation therapy; QOL: quality of life.

Adjusting for gender and nodal status with a multiple linear regression model, FC was significantly associated with change in financial difficulty $(\beta=-0.204 \pm 0.096, p=0.035)$ 
(Table 4). Therefore, patients who received FC had a 0.2 units lower change in financial difficulty score on average, compared with those with the same gender and nodal stage but without FC.

Table 4. Multiple linear regression model for change in financial difficulty.

\begin{tabular}{cccc}
\hline Variable & $\boldsymbol{\beta}$ & SE & $p$-Value \\
\hline Female & -0.2068 & 0.0999 & 0.0391 \\
N stage & & & \\
N0 & reference & & \\
N1 & 0.2783 & 0.1247 & 0.0263 \\
N2 & 0.2314 & 0.1085 & 0.0336 \\
N3 & 0.3695 & 0.1604 & 0.0218 \\
Financial Counseling & -0.2039 & 0.0964 & 0.0351 \\
\hline
\end{tabular}

SE: standard error; F-test of overall significance: $p=0.0054 ; \mathrm{R}^{2}=0.04$.

\section{Discussion}

In this study, unsurprisingly, routine utilization of financial counselor was associated with a significant increase in the number of patients receiving FC (5.3\% vs. 62.7\%, $p<0.0001)$. Financial difficulty scores at the end of treatment, as compared with baseline, were significantly higher in patients without FC $(p=0.002)$, but not in those with FC $(p=0.588)$. The multiple linear regression analysis showed a significant effect of FC on the change in financial difficulty scores after adjusting for gender and nodal status. The result suggests that, for patients of the same gender and nodal status, receiving FC will reduce the change in financial difficulty score by 0.2 units, on average.

FT is associated with the decline of QOL as well as increased mortality, possibly through a hesitancy to pursue additional treatment or non-compliance [9-11,21-23].

Despite numerous calls to reduce healthcare costs in the United States, this extremely complex issue will require a multifaceted approach to correct and is likely to worsen in the short term $[4,24,25]$. One solution to reduce FT is to consider the clinical benefit of new interventions not just against adverse reactions, but also to consider the cost and potential for FT [24]. Current studies of de-escalation of treatment in HNC do factor cost-savings as well [26].

FC provides transparency and clarity for a complex medical system during a stressful time in patients' life $[4,25,27]$. Furthermore, unlike modifications of standard therapeutic regimens, the introduction of non-treatment-based interventions to address FT are unlikely to compromise oncologic outcomes. While some have proposed the utility of FC to ameliorate FT, empiric investigation is typically limited to small pilot studies [27-31].

Even though FC was possible, the presence of a full-time employee dedicated to this task and screening all outpatients was clearly beneficial as the proportion of patients receiving FC increased significantly (5.3\% vs. $62.7 \%$ ). As seen with a previous study, awareness, ease of access, and availability are critical to helping overcome barriers preventing from patients receiving FC [27].

Interestingly, while patients who underwent FC were more likely to be married or formerly married and treated with fewer fractions, these factors were not associated with financial difficulty in the regression model. As patients who underwent FC were more likely to have a lower nodal stage, it is vital to account for this association, as increased nodal stage was associated with a greater difference between post-treatment and pretreatment financial difficulty scores. As the use of multiple treatment modalities was not associated with change in financial difficulty scores, the mechanism behind the association between nodal status and FT is unclear.

In contrast to our findings, randomization to FC was not associated with reduced FT in a previous 95-patient randomized study of patients with metastatic gastrointestinal or lung cancer planned for chemotherapy, who were randomly assigned to receive FC versus no intervention [27]. Notably, only $30 \%$ of patients randomized to FC actually completed 
the full, two-part intervention (in-person and phone counseling) [27]. While another pilot study in non-metastatic solid tumor patients also had difficulty with compliance (59\%), financial navigation was association with a reduction in high levels of financial concern [28]. Moreover, in a non-cancer population, the implementation of financial navigation strategies improved patient satisfaction care and cost-concerns [29]. Interestingly, when caregivers were also included in financial navigation, participation rate increased to $78 \%$, suggesting targeting the patient-caregiver dyad is a more effective strategy to implement FC [30].

A limitation to the current study is the use of a single-item question within the EORTCQLQ-C30 to assess financial difficulty, whereas others have proposed more comprehensive questionnaires including the comprehensive score for financial toxicity (COST), Personal Financial Wellness Scale, the Patient Self-Administered Financial Effects (P-SAFE), as well as an HNC specific survey, the Financial index of Toxicity (FIT) [31-34]. Furthermore, the causes and consequences of financial difficulty are not characterized in this study. While plans to incorporate a more detailed measure in our clinical evaluation are underway, the single-item financial difficulty question may have use as a screening item to identify those who would benefit from additional financial information.

Additional limitations include potential selection bias in the patients who received FC versus those who did not. Moreover, this analysis was unable to account for median income, employment status, and education level among patients.

Finally, during this study period, no other department at our institution employed a dedicated financial counselor. However, based in part on the findings of this manuscript, our institution plans to implement financial counseling in different clinics as part of a project sponsored by the National Institutes of Health.

\section{Conclusions}

Providing a dedicated financial counselor significantly increased the proportion of $\mathrm{HNC}$ receiving FC, resulting in the stabilization of financial difficulty scores post-treatment. Based on a multiple linear regression model, FC was independently associated with reduced financial difficulty. The employment of a financial counselor may be a viable, hospital-based approach to begin to address FT in HNC.

Supplementary Materials: The following are available online at https: / www.mdpi.com/article/10 $.3390 /$ cancers13112516/s1, Supplemental document 1: understanding your health insurance benefits.

Author Contributions: Conceptualization, M.R.M., A.D.R., E.A.R. and A.K.S.; Data curation, M.F., H.Y., S.J.M., A.J.I., K.E., E.W., K.A., R.P.M., J.M.C., W.L.H.J., M.E.P., A.D.R., E.A.R. and A.K.S.; Formal analysis, M.F., H.Y., K.A. and A.K.S.; Funding acquisition, A.K.S.; Investigation, M.F., K.E., E.W., K.E.W., V.G., R.P.M., M.A.K., M.R.M., J.M.C., W.L.H.J., M.E.P., A.D.R., E.A.R. and A.K.S.; Methodology, M.F., H.Y., K.A. and A.K.S.; Project administration, A.K.S.; Resources, A.K.S.; Supervision, A.K.S.; Visualization, V.G.; Writing-original draft, M.F., H.Y., S.J.M., A.J.I., K.E., E.W., K.A., K.E.W., R.P.M., M.A.K., M.R.M., J.M.C., W.L.H.J., M.E.P., A.D.R., E.A.R. and A.K.S.; Writing-review \& editing, M.F., S.J.M., A.D.R., E.A.R. and A.K.S. All authors have read and agreed to the published version of the manuscript.

Funding: This work was supported by the National Cancer Institute Cancer Center Support Grant (P30CA016056).

Institutional Review Board Statement: The study was conducted according to the guidelines of the Declaration of Helsinki and approved by the Institutional Review Board of Roswell Park Comprehensive Cancer Center (EDR 103707 3/18/2021).

Informed Consent Statement: A waiver of consent was obtained from the Institutional Review Board due to the retrospective nature of the study making consent impractical, and contacting patients to obtain consent would pose a greater risk than the waiver.

Data Availability Statement: Farrugia, Yu, and Singh had full access to all the data in the study and take responsibility for the integrity of the data and the accuracy of the data analysis. The data underlying this article cannot be shared publicly for the privacy of individuals that participated in the study. The data are available from the corresponding author upon reasonable request. 
Acknowledgments: We would like to thank Kelsey Smith PA for her continued efforts in the excellent care of these patients. Additionally, we acknowledge the work of Erica Innocent and Kellie Boyd in the financial counseling of our patients. Lastly, we recognize Michael Kuettel for his efforts in the installation and optimization of the financial counseling process.

Conflicts of Interest: There are no financial disclosures or conflict of interest from any of the authors.

\section{References}

1. Chang, P.Y.; Huang, W.Y.; Lin, C.L.; Huang, T.C.; Wu, Y.Y.; Chen, J.H.; Kao, C.H. Propranolol Reduces Cancer Risk: A PopulationBased Cohort Study. Medicine 2015, 94, e1097. [CrossRef] [PubMed]

2. Altice, C.K.; Banegas, M.P.; Tucker-Seeley, R.D.; Yabroff, K.R. Financial Hardships Experienced by Cancer Survivors: A Systematic Review. J. Natl. Cancer Inst. 2017, 109. [CrossRef] [PubMed]

3. Mariotto, A.B.; Yabroff, K.R.; Shao, Y.; Feuer, E.J.; Brown, M.L. Projections of the cost of cancer care in the United States: 2010-2020. J. Natl. Cancer Inst. 2011, 103, 117-128. [CrossRef] [PubMed]

4. Desai, A.; Gyawali, B. Financial toxicity of cancer treatment: Moving the discussion from acknowledgement of the problem to identifying solutions. EClinicalMedicine 2020, 20, 100269. [CrossRef] [PubMed]

5. Pearce, A.M.; Hanly, P.; Timmons, A.; Walsh, P.M.; O’Neill, C.; O'Sullivan, E.; Gooberman-Hill, R.; Thomas, A.A.; Gallagher, P.; Sharp, L. Productivity Losses Associated with Head and Neck Cancer Using the Human Capital and Friction Cost Approaches. Appl. Health Econ. Health Policy 2015, 13, 359-367. [CrossRef]

6. Massa, S.T.; Osazuwa-Peters, N.; Adjei Boakye, E.; Walker, R.J.; Ward, G.M. Comparison of the Financial Burden of Survivors of Head and Neck Cancer With Other Cancer Survivors. JAMA Otolaryngol. Head Neck Surg. 2019, 145, 239-249. [CrossRef] [PubMed]

7. de Souza, J.A.; Kung, S.; O'Connor, J.; Yap, B.J. Determinants of Patient-Centered Financial Stress in Patients With Locally Advanced Head and Neck Cancer. J. Oncol. Pract. 2017, 13, e310-e318. [CrossRef]

8. Jacobson, J.J.; Epstein, J.B.; Eichmiller, F.C.; Gibson, T.B.; Carls, G.S.; Vogtmann, E.; Wang, S.; Murphy, B. The cost burden of oral, oral pharyngeal, and salivary gland cancers in three groups: Commercial insurance, Medicare, and Medicaid. Head Neck Oncol. 2012, 4, 15. [CrossRef]

9. Rogers, S.N.; Harvey-Woodworth, C.N.; Hare, J.; Leong, P.; Lowe, D. Patients' perception of the financial impact of head and neck cancer and the relationship to health related quality of life. Br. J. Oral Maxillofac. Surg. 2012, 50, 410-416. [CrossRef]

10. Ma, S.J.; Iovoli, A.J.; Attwood, K.; Wooten, K.E.; Arshad, H.; Gupta, V.; McSpadden, R.P.; Kuriakose, M.A.; Markiewicz, M.R.; Chan, J.M.; et al. Association of significant financial burden with survival for head and neck cancer patients treated with radiation therapy. Oral Oncol. 2021, 115, 105196. [CrossRef]

11. Beeler, W.H.; Bellile, E.L.; Casper, K.A.; Jaworski, E.; Burger, N.J.; Malloy, K.M.; Spector, M.E.; Shuman, A.G.; Rosko, A.; Stucken, C.L.; et al. Patient-reported financial toxicity and adverse medical consequences in head and neck cancer. Oral Oncol. 2020, 101, 104521. [CrossRef]

12. Cherny, N.I.; Dafni, U.; Bogaerts, J.; Latino, N.J.; Pentheroudakis, G.; Douillard, J.Y.; Tabernero, J.; Zielinski, C.; Piccart, M.J.; de Vries, E.G.E. ESMO-Magnitude of Clinical Benefit Scale version 1.1. Ann. Oncol. 2017, 28, 2340-2366. [CrossRef] [PubMed]

13. Schnipper, L.E.; Davidson, N.E.; Wollins, D.S.; Blayney, D.W.; Dicker, A.P.; Ganz, P.A.; Hoverman, J.R.; Langdon, R.; Lyman, G.H.; Meropol, N.J.; et al. Updating the American Society of Clinical Oncology Value Framework: Revisions and Reflections in Response to Comments Received. J. Clin. Oncol. 2016, 34, 2925-2934. [CrossRef] [PubMed]

14. Choosing Wisely Campaign. Available online: https://www.choosingwisely.org/ (accessed on 9 April 2021).

15. de Moor, J.S.; Mollica, M.; Sampson, A.; Adjei, B.; Weaver, S.J.; Geiger, A.M.; Kramer, B.S.; Grenen, E.; Miscally, M.; Ciolino, H.P. Delivery of Financial Navigation Services within National Cancer Institute-Designated Cancer Centers. JNCI Cancer Spectr. 2021. [CrossRef]

16. Hermann, G.M.; Iovoli, A.J.; Platek, A.J.; Wang, C.; Miller, A.; Attwood, K.; Bourgeois, D.J.; Singh, A.K. A single-institution, randomized, pilot study evaluating the efficacy of gabapentin and methadone for patients undergoing chemoradiation for head and neck squamous cell cancer. Cancer 2020, 126, 1480-1491. [CrossRef] [PubMed]

17. Platek, M.E.; McCloskey, S.A.; Cruz, M.; Burke, M.S.; Reid, M.E.; Wilding, G.E.; Rigual, N.R.; Popat, S.R.; Loree, T.R.; Gupta, V.; et al. Quantification of the effect of treatment duration on local-regional failure after definitive concurrent chemotherapy and intensity-modulated radiation therapy for squamous cell carcinoma of the head and neck. Head Neck 2013, 35, 684-688. [CrossRef]

18. Fung-Kee-Fung, S.D.; Hackett, R.; Hales, L.; Warren, G.; Singh, A.K. A prospective trial of volumetric intensity-modulated arc therapy vs conventional intensity modulated radiation therapy in advanced head and neck cancer. World J. Clin. Oncol. 2012, 3, 57-62. [CrossRef]

19. Fayers, P.M.; Aaronson, N.K.; Bjordal, K.; Groenvold, M.; Curran, D.; Bottomley, A.; EORTC Quality of Life Group. The EORTC QLQ-C30 Scoring Manual, 3rd ed.; European Organisation for Research and Treatment of Cancer: Brussels, Belgium, 2001.

20. Scoring of the QLQ-C30 Summary Score. Available online: https://qol.eortc.org/app/uploads/sites/2/2018/02/scoring_of_ the_qlq-c30_summary_score.pdf (accessed on 11 May 2021).

21. Ramsey, S.D.; Bansal, A.; Fedorenko, C.R.; Blough, D.K.; Overstreet, K.A.; Shankaran, V.; Newcomb, P. Financial Insolvency as a Risk Factor for Early Mortality Among Patients With Cancer. J. Clin. Oncol. 2016, 34, 980-986. [CrossRef] 
22. Farrugia, M.; Yu, H.; Ma, S.J.; Iovoli, A.J.; Attwood, K.; Wooten, K.E.; Arshad, H.; Gupta, V.; McSpadden, R.P.; Kuriakose, M.A.; et al. A Principal Component of Quality of Life Measures Is Associated with Survival for Head and Neck Cancer Patients Treated with Radiation Therapy. Cancers 2021, 13, 1155. [CrossRef]

23. Kale, H.P.; Carroll, N.V. Self-reported financial burden of cancer care and its effect on physical and mental health-related quality of life among US cancer survivors. Cancer 2016, 122, 283-289. [CrossRef]

24. Ratain, M.J.; Goldstein, D.A.; Lichter, A.S. Interventional Pharmacoeconomics-A New Discipline for a Cost-Constrained Environment. JAMA Oncol. 2019, 5, 1097-1098. [CrossRef] [PubMed]

25. Shankaran, V.; Ramsey, S. Addressing the Financial Burden of Cancer Treatment: From Copay to Can't Pay. JAMA Oncol. 2015, 1, 273-274. [CrossRef]

26. Ma, D.J.; Price, K.A.; Moore, E.J.; Patel, S.H.; Hinni, M.L.; Garcia, J.J.; Graner, D.E.; Foster, N.R.; Ginos, B.; Neben-Wittich, M.; et al. Phase II Evaluation of Aggressive Dose De-Escalation for Adjuvant Chemoradiotherapy in Human Papillomavirus-Associated Oropharynx Squamous Cell Carcinoma. J. Clin. Oncol. 2019, 37, 1909-1918. [CrossRef] [PubMed]

27. Kircher, S.M.; Yarber, J.; Rutsohn, J.; Guevara, Y.; Lyleroehr, M.; Alphs Jackson, H.; Walradt, J.; Desai, B.; Mulcahy, M.; Kalyan, A.; et al. Piloting a Financial Counseling Intervention for Patients With Cancer Receiving Chemotherapy. J. Oncol. Pract. 2019, 15, e202-e210. [CrossRef]

28. Shankaran, V.; Leahy, T.; Steelquist, J.; Watabayashi, K.; Linden, H.; Ramsey, S.; Schwartz, N.; Kreizenbeck, K.; Nelson, J.; Balch, A.; et al. Pilot Feasibility Study of an Oncology Financial Navigation Program. J. Oncol. Pract. 2018, 14, e122-e129. [CrossRef]

29. Banegas, M.P.; Dickerson, J.F.; Friedman, N.L.; Mosen, D.; Ender, A.X.; Chang, T.R.; Runge, T.A.; Hornbrook, M.C. Evaluation of a Novel Financial Navigator Pilot to Address Patient Concerns about Medical Care Costs. Perm. J. 2019, 23, 18-084. [CrossRef]

30. Watabayashi, K.; Steelquist, J.; Overstreet, K.A.; Leahy, A.; Bradshaw, E.; Gallagher, K.D.; Balch, A.J.; Lobb, R.; Lavell, L.; Linden, H.; et al. A Pilot Study of a Comprehensive Financial Navigation Program in Patients With Cancer and Caregivers. J. Natl. Compr. Canc. Netw. 2020, 18, 1366-1373. [CrossRef]

31. de Souza, J.A.; Yap, B.J.; Wroblewski, K.; Blinder, V.; Araujo, F.S.; Hlubocky, F.J.; Nicholas, L.H.; O'Connor, J.M.; Brockstein, B.; Ratain, M.J.; et al. Measuring financial toxicity as a clinically relevant patient-reported outcome: The validation of the COmprehensive Score for financial Toxicity (COST). Cancer 2017, 123, 476-484. [CrossRef]

32. Hueniken, K.; Douglas, C.M.; Jethwa, A.R.; Mirshams, M.; Eng, L.; Hope, A.; Chepeha, D.B.; Goldstein, D.P.; Ringash, J.; Hansen, A.; et al. Measuring financial toxicity incurred after treatment of head and neck cancer: Development and validation of the Financial Index of Toxicity questionnaire. Cancer 2020, 126, 4042-4050. [CrossRef]

33. Meisenberg, B.R.; Varner, A.; Ellis, E.; Ebner, S.; Moxley, J.; Siegrist, E.; Weng, D. Patient Attitudes Regarding the Cost of Illness in Cancer Care. Oncologist 2015, 20, 1199-1204. [CrossRef] [PubMed]

34. Tremblay, D.; Poder, T.G.; Vasiliadis, H.M.; Touati, N.; Fortin, B.; Levesque, L.; Longo, C. Translation and Cultural Adaptation of the Patient Self-Administered Financial Effects (P-SAFE) Questionnaire to Assess the Financial Burden of Cancer in FrenchSpeaking Patients. Healthcare 2020, 8, 366. [CrossRef] 